\title{
Analysis of the correlations between freeze-thaw and salt crystallization tests
}

\author{
V. Cárdenes • F. J. Mateos • S. Fernández-Lorenzo
}

Received: 10 December 2012/Accepted: 22 April 2013/Published online: 11 August 2013

(C) Springer-Verlag Berlin Heidelberg 2013

\begin{abstract}
Two of the most popular weathering tests used for dimension stone are EN 12371 freeze-thaw (FT) and EN 12370 Salt Crystallization (SC). These tests are used to assign a durability value to the rocks. Both tests are based on the cyclical growth of crystals in the porous system of the rock, which causes structural stress on the rock matrix that may affect its integrity. The weathering mechanism is the same in both tests although the rate of volume increase is higher for the salt crystals. Due to this similarity, the two tests provide complementary information. The EN (European Norms) recommend evaluating the results together, but do not establish correlations between the results of these two tests for different types of rocks. Knowing these relationships would improve the understanding of the results and the response to weathering of the rock once placed in a building. In this work, several ornamental rocks (sandstones, limestones, dolostones, and a travertine) from the Iberian Peninsula were submitted to FT and SC tests. Rocks were mineralogically and petrographically characterized, and their porous systems were defined by a combination of techniques (scanning electronic microscopy, digital images analysis, and mercury porosimetry). The results of the tests were quantified numerically to compare them. The velocity of propagation of ultrasonic waves was measured before and after the tests. After the statistical analysis, significant correlations were found between the
\end{abstract}

V. Cárdenes $(\bowtie)$

Área de Petrología, Dpto. Geología, Universidad de Oviedo, Jesús Arias de Velasco, 33005 Oviedo, Spain

e-mail: victor@valdeorras.com

F. J. Mateos · S. Fernández-Lorenzo

Gea Asesoría Geológica, Polígono de Silvota, c/Peña Beza, nave 16, 33192 Llanera, Spain
FT and SC tests, and between the connected porosity and the durability index of the rocks.

Keywords Salt crystallization · Freeze-thaw · Dimension stone $\cdot$ Durability $\cdot$ Weathering

\section{Introduction}

Predicting the response of a dimension stone to environmental weathering is a key factor for assessing a construction's lifespan. The performance of the stone is determined by its function and location of the construction, and by the environmental agents (humidity, seasonal changes, temperature variation, etc.) present. In order to predict the behavior of the stone, several standard tests have been developed (Bortz and Wonneberger 2000). Two of the most popular weathering tests are salt crystallization (SC) and freeze-thaw (FT) (Carr et al. 1996). Both tests follow the same mechanism: filling the pore system of the rock with an aqueous phase that increases its volume, due to salt crystallization in the case of the SC test, or due to freezing in the FT test. These steps are meant to be one cycle. Both tests have their corresponding versions for the ASTM (C128) and EN $(12370,12371)$ norms. Since these tests both deal with similar type of rocks, they have frequently been used together or even substituted each other depending on time constraints. This is not correct and may lead to inaccurate conclusions.

Fluid weathering on a rock may act both at a chemical level and at a physical level. Chemical level refers to all the changes in which the composition of the fluid interacts with the composition of the rock, e.g., dissolution of carbonated minerals or oxidation of iron minerals. Physical level refers to the changes in which there are no interaction between 
the composition of the rock and the composition of the fluid, e.g. gelifraction. The physical mechanism is more harmful for the integrity of the rock (Benavente et al. 2007), which is a function of several factors intrinsic to the rock on the one hand, such as pore size distribution (PSD), saturation, connected porosity, tortuosity, crystallization pressure, and connectivity, and other factors intrinsic to the fluid on the other, particularly surface tension and temperature. In the case of the SC test, the nature of the salt also plays an important role in weathering. The salt used in the EN 12370 Determination of resistance to salt crystallization is sodium sulfate decahydrate $\left(\mathrm{Na}_{2} \mathrm{SO}_{4} \cdot 10 \mathrm{H}_{2} \mathrm{O}\right)$. Lithology is also an important factor in weathering. Alves et al. (2011) points out that, for high porosity values, carbonates (limestones and dolostones), marbles, and granites have low durability, in this order.

Each author gives more or less importance to each factor, but in general, PSD is considered the main trigger for weathering. In fact, this is obvious, since PSD influences the rest of rocks' intrinsic factors. For the SC test, there are several weathering indices developed by different authors, all of which take into account the PSD. For example, Matsukura and Matsuoka (1996) define their Weathering Susceptibility Index as the relationship between the crystallization pressure and PSD in various types of rocks. Ordoñez et al. (1997) define their durability dimension estimator as the relationship between the PSD and connected porosity in limestones, while Benavente et al. (2004) enhanced this index by creating the petrophysical durability estimator, which also takes into account the material's strength characteristics in various types of carbonates and sandstones. Angeli et al. (2007) used the Alteration Index in limestones and sandstones as the number of cycles until the first visible damage occurred, which is a function of the water circulation through the rock bulk. Last, Yu and Oguchi (2010) define the Salt Susceptibility Index as a function of PSD in various types of rock. However, while all of these indices can predict the behavior of some types of rock submitted to SC test, none of them can be considered universal (Benavente et al. 2004).

Angeli et al. (2007) identify three stages of weathering for the SC test: an initial stage, where the samples gains weight due to the addition of salt to the pores, a second stage where the weight loss of the rock mass is in balance with the weight gain due to salt crystallization, and finally a third stage where the weight loss is dominant, following a linear evolution. $\mathrm{T}$ is an important parameter for the SC test, as it is negatively correlated with alteration (Angeli et al. 2010) for the range of $5-30{ }^{\circ} \mathrm{C}$. Benavente et al. (2007) found that in several types of rock, weathering, measured as weight loss, follows a negative correlation with compressive strength, P-wave velocity, and the mean pore access radius. Additionally, SC does not modify the pore system of the rocks in a significant way (Angeli et al. 2008).

The FT test is used to assess the integrity of rocks and other materials in cold regions and especially in semi-cold regions, as in Western Europe, where the frequency of FT cycles is quite high. FT acts in a very similar way to the SC test by causing crystals to grow in the pore system of the rock. In the freeze phase, water stored in micropores $(<10 \mu \mathrm{m})$ undergoes a volume expansion of $9 \%$ (Takarli et al. 2008; Ruedrich et al. 2011), producing tensile stress and damage in the micropores. During the thaw phase, the water flows through the fractured micropores and increases the damage. Nevertheless, it is generally observed that the rate of the damage decreases over successive FT cycles, but it is continuous until the failure of the rock. However, this fact depends greatly on the type of rock observed.

Takarli et al. (2008) observed that the flow of fluids through the rock matrix decreases over the course of the FT test, which indicates a modification of the connected porous network. Rocks with low permeability, in which water flows with difficulty, are more susceptible to damage, due to a poor reorganization of the rock matrix while freezing, which leads to significant differential stress (Saad et al. 2010). However, this depends on other rock properties. For some high porous limestones, the potential frost damage can be very high, whilst low porous sandstones might be very resistant to this kind of weathering. For sandstones, the performance against weathering is determined by the texture of the rock, which is closely linked with the effective porosity and by the type of cement. Thus, for sandstones with silica cement the main factor is the pore system structure, whilst in sandstones with clay cement it is more important the mineral composition of the rock (Labus and Biochen 2012).

A careful review of the available literature highlights some apparent contradictions in the importance and effect of the weathering mechanisms (Alves et al. 2011). For example, some authors (Benavente et al. 2007) argue that crystallization inside the pore system is favored by lower capillary kinetics, which in turn causes weathering. Yet, for other authors (Oguchi and Yuasa 2010), it is high capillary kinetics that promotes weathering by creating wide and fast access to the pore system. Thus, the literature contains abundant disagreements as to the mechanisms and results of the tests, even in studies conducted with the same type of rock (Alves et al. 2011; Mutlutürk et al. 2004). These, and other contradictions, can be summed up as follows: the performance of the rocks in front of weathering do not always follow the same path, and the final results may not be the expected ones. Of course there are general tendencies for the different types of rocks (sedimentary, metamorphic and igneous), but a closer examination will show 
results with a huge degree of variation even for aliquot samples of the same rock. Proof of this is the very number of different weathering indices proposed by various authors.

The salt crystallization test versus the freeze-thaw test

Differences between both tests can be found in the surface tension $\sigma$ and crystallization pressure parameters of the fluids. For sodium sulfate decahydrate, $\sigma=0.046 \mathrm{~N} / \mathrm{m}$ (La Iglesia et al. 1997), while for water, $\sigma=0.0728 \mathrm{~N} / \mathrm{m}$ (Stumm and Morgan 1981). Crystallization pressure depends on the radius of the coarse $(R)$ and small $(r)$ connected pores, and surface tension $(\sigma)$, depends on both fluid and rock as follows:

Crystallization pressure $=2 \sigma(1 / r-1 / R)$

(La Iglesia et al. 1997).

Therefore, for the same rock, crystallization pressure should be higher for water than for salt.

This fact may lead one to assume that FT is more harmful than SC, contrary to the findings of numerous studies, e.g. (Akin and Özsan 2011 and Přikryl et al. 2003). This disagreement is due to the fact that weathering is related to other factors, as pointed out above. Also, Steiger et al. (2011) consider that both crystallization pressures are equivalent in terms of influence on the crystal growth inside the pore system. In nature, both processes usually occur at the same time, since water frequently contains salts in solution, a combination that accelerates weathering processes.

For Benavente (2011) and Benavente et al. (2007), there are two important pore throat intervals in terms of crystallization stress. Since weathering is more aggressive in rocks with micropores due to the effect of capillarity, rocks with pore throats between 0.1 and $10 \mu \mathrm{m}$ are considerably affected by the weathering induced by both SC and FT. However, the SC test is considered to be the most aggressive weathering mechanism for rocks (Alves et al. 2011; Angeli et al. 2010; Buj et al. 2010). Also, weathering by SC can be found in all the earth's environments, from the poles to the deserts (Doehne 2002), while FT weathering is restricted to areas with temperatures below $0{ }^{\circ} \mathrm{C}$.

While in the scientific literature it is relatively common to find studies using both tests, and analyzing the response of a specific rock to them, it is not so easy to find studies that compare the effects of both tests on the same rocks. It has been assumed by some researchers that the results of both tests are almost equivalent, and choosing of one test or the other is only determined by the available time and laboratory facilities. Along these lines, Goudie (1999) develops a first comparison study for both tests, finding that limestones do not respond in the same way to the two tests, with no correlation. He quantified the degree of weathering during the tests by measuring the remaining weight of the samples after each cycle. In general, weighing the samples over the course of the cycles is the most accepted method for monitoring the evolution during the weathering tests and has been used in several studies.

\section{Materials and methods}

\section{Rock samples}

Nineteen varieties of sedimentary building stones were chosen for this study (Table 1). Samples were selected in accordance with their importance in the stone market, their use in Spanish historical buildings, and their characteristic porous system. In geological terms, they are all to be found in the Tertiary basins of the Iberian Peninsula (Fig. 1).

LSP and PMU are dolostone and limestone, respectively, quarried in Asturias, Northern Spain, and widely used in the construction of the area's historical buildings, such as the Cathedral of Oviedo or the Santa Maria del Naranco Palace. While today these quarries have both been exhausted, the samples used in this study were taken from the historical batch held in the Universidad de Oviedo's Department of Geology. SIL, BRY, and VLD are dolostones that are very common in the examples of historical Roman architecture scattered along the Pilgrim's Way to Santiago; in the North of Spain SIL has a characteristic microporous texture, while BRY and VLD have a macroporous texture. SIL is used today as the equivalent for LSP in restoration work, while BRY and VLD are used as substitutes for PMU. HNT, NWY, and LRS are limestone lumachelles with a macroporous texture and are very common in the historical buildings of southeastern Spain (NWY and LRS) and in northern Spain. RSS is a pink sandstone quarried near Madrid, in the province of Segovia, and is used mainly in new buildings. Bateig stones (BAM, BAZ, and BAF) come from Mt. Bateig in Elda, Alicante. The stones quarried from this mountain have lithologies that run from terrigenous terms, like BAF, to carbonate terms, like BAZ and BAM. These stones are relatively new in the stone market and are becoming very popular. For example, the BAZ variety, or Blue Bateig, is used by the textile chain store "Zara" for flooring all its premises worldwide. PAG, ESP, and DOU are two sandstones that come from the same formation in the province of Palencia in northern Spain. They are popular in historical and modern buildings alike, as for OJP and PIT, which are quarried in the provinces of La Rioja and Navarra. Last, PCF and AVF are two very popular sandstones in certain regions of Catalonia, with a small but continuous regional market (Table 1). 
Table 1 Rocks used in this work

\begin{tabular}{|c|c|c|c|c|}
\hline Sample & Commercial name & Location & Estimated production (ton/year) & Uses \\
\hline ESP & Espinosa Stone & Espinosa (Burgos) & 5.000 & $\mathrm{c}, \mathrm{R}, \mathrm{H}$ \\
\hline PCF & Rocafort Stone & Monistrol (Catanlunya) & 6.300 & $\mathrm{C}, \mathrm{H}$ \\
\hline OJP & Ojo de Perdiz Sandstone & Aldehuela (Soria) & 9.560 & $\mathrm{c}, \mathrm{R}, \mathrm{H}$ \\
\hline PIT & Pitillas Stone & Pitillas (Navarra) & 2.800 & $\mathrm{c}, \mathrm{R}, \mathrm{H}$ \\
\hline BAF & Fantasy Bateig & Elda (Alicante) & 26.300 & $\mathrm{C}$ \\
\hline AVF & Folgueroles Green Sandstone & Folgueroles (Catalunya) & 4.400 & $\mathrm{C}, \mathrm{r}, \mathrm{H}$ \\
\hline VLD & Valdivielso Dolostone & Condado (Burgos) & 12.100 & $\mathrm{C}, \mathrm{R}$ \\
\hline SIL & Silos Stone & Silos (Burgos) & 16.000 & $\mathrm{C}, \mathrm{r}, \mathrm{H}$ \\
\hline BRY & Bernuy Stone & Bernuy (Segovia) & NQ & $\mathrm{H}$ \\
\hline BAM & Yellow Bateig & Elda (Alicante) & 41.200 & $\mathrm{C}$ \\
\hline BAZ & Blue Bateig & Elda (Alicante) & 56.000 & $\mathrm{C}$ \\
\hline NWY & Niwala Yellow & Nervio (Albacete) & 4.200 & $\mathrm{C}, \mathrm{H}$ \\
\hline PAG & Aguilar Stone & Quintanilla (Palencia) & 2.800 & $\mathrm{C}, \mathrm{r}, \mathrm{h}$ \\
\hline DOU & Golden Urbión & Vilviestre (Burgos) & 13.600 & $\mathrm{C}, \mathrm{r}, \mathrm{h}$ \\
\hline LSP & Laspra Dolostone & Oviedo (Asturias) & NQ & $\mathrm{H}$ \\
\hline PMU & Piedramuelle Limestone & Piedramuelle (Asturias) & NQ & $\mathrm{H}$ \\
\hline HNT & Hontoria Stone & Hontoria (Burgos) & 8.800 & $\mathrm{C}, \mathrm{H}$ \\
\hline RSS & Pink Sepúlveda & Sepúlveda (Segovia) & 13.000 & $\mathrm{C}, \mathrm{r}, \mathrm{h}$ \\
\hline LRS & Pink Lumachelle & Albatana (Albacete) & 8.000 & $\mathrm{C}, \mathrm{H}$ \\
\hline
\end{tabular}

Use of upper-case or lower-case shows the predominance of one use among the others

$N Q$ not quarried nowadays, $C$ construction, $R$ restoration, $H$ cultural heritage

Fig. 1 Location of the rock samples in the Iberian Peninsula

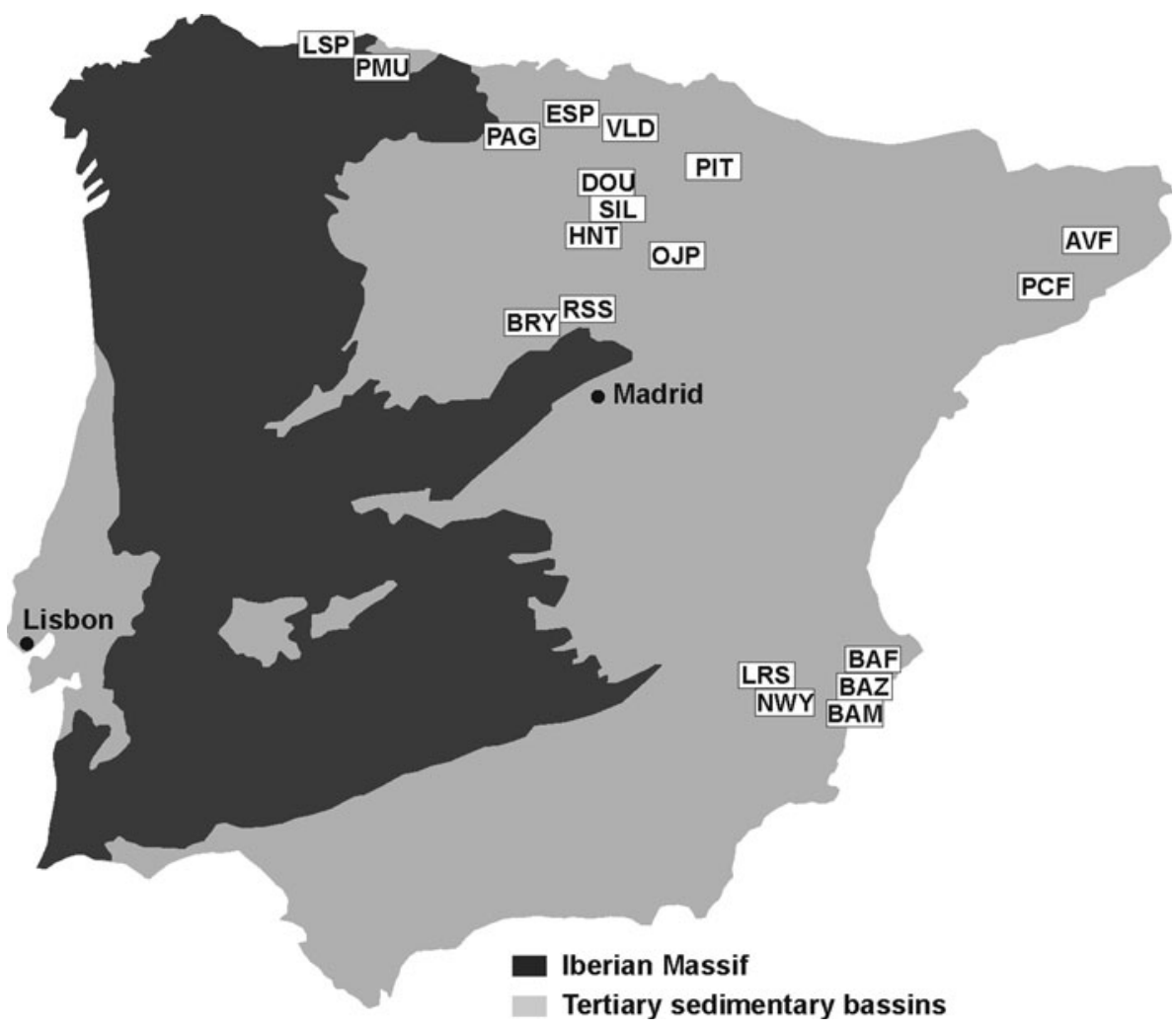


Fig. 2 Different stages of alteration considered in this work. From left to right, no alteration ( $\operatorname{score}=2$ ), significant alteration (score $=1)$, and sample destroyed $($ score $=0)$
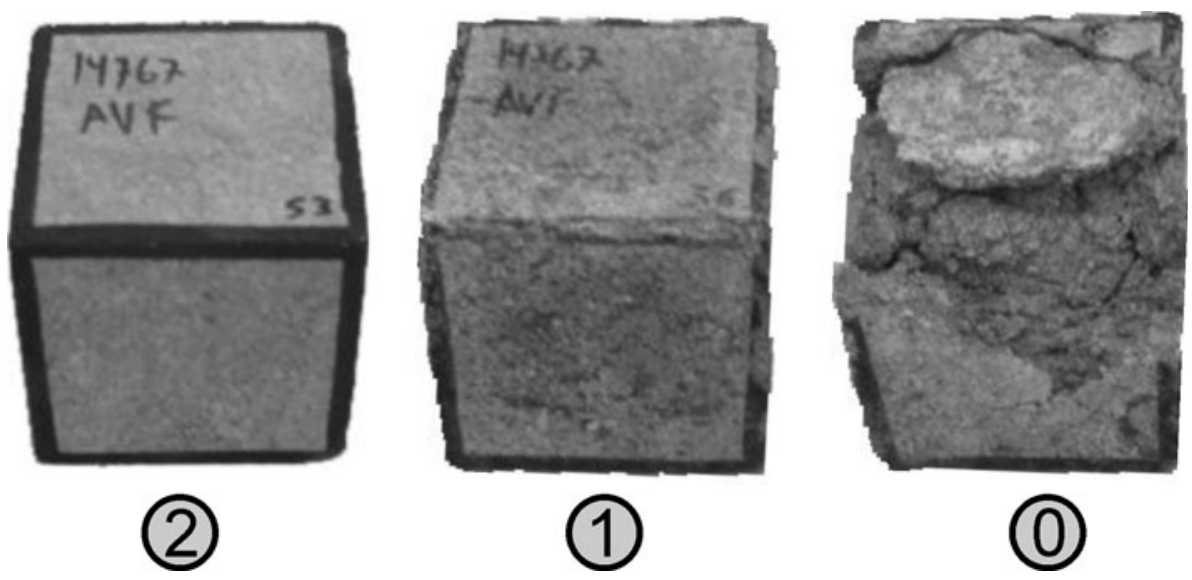

Table 2 Type, texture and main mineral proportions of the samples

$Q z t$ quartz, $M$ mica, Cal calcite, $G$ goethite, Dol dolomite, Ank ankerite

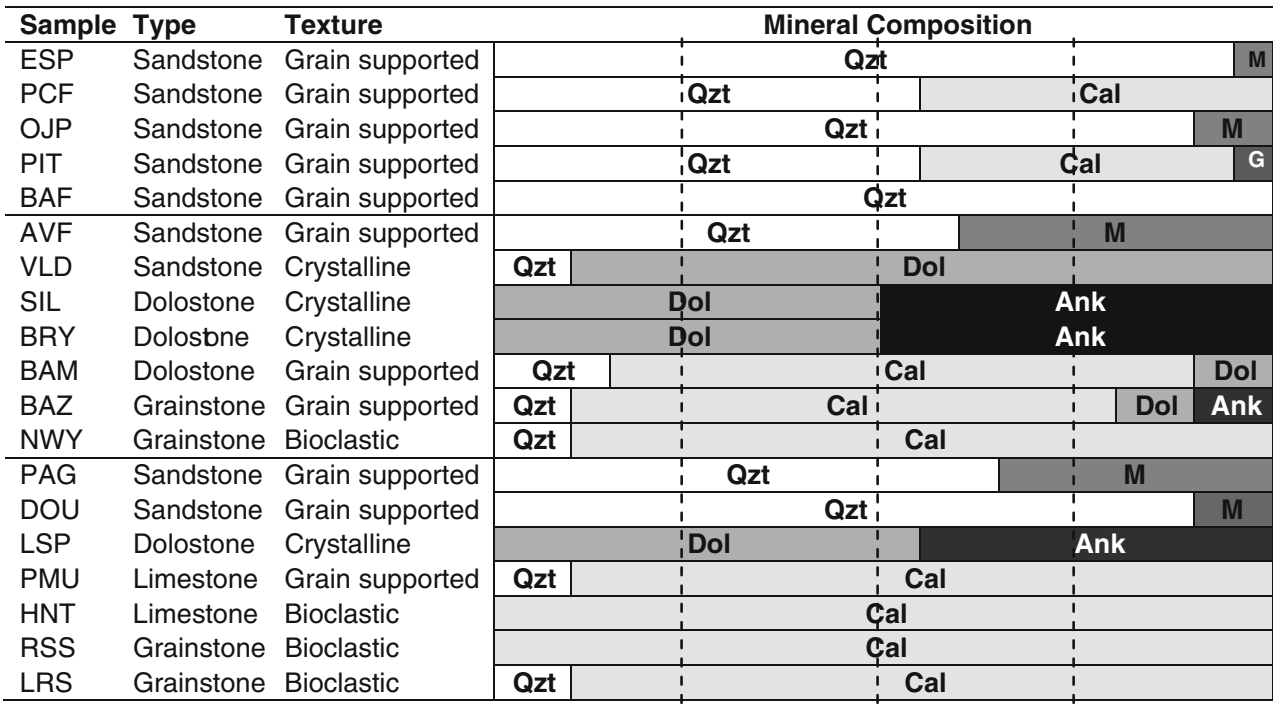

Methods

\section{Petrophysical characterization}

The petrological examination of the samples was carried out by means of transmitted light microscopy. To this end, thin $30 \mu \mathrm{m}$ thick sections were prepared and examined with a Carl-Zeiss ${ }^{\circledR}$ Universal Polarized Light microscope. Thin section images were taken with a Leica DC $300 \mathrm{~F}$ camera. These petrographical analyses were supplemented with mineralogical semi-quantification by X-ray diffraction (XRD). The XRD analyses were carried out using a Philips PW 1830 diffractometer, with a $\mathrm{Cu}$ cathode with wavelength of $\mathrm{K} \alpha=1.54051$. The angular scan was recorded from $2^{\circ}$ to $15^{\circ} 2 \theta$ with a Philips PW 1710 digital recorder. The diffractograms obtained were studied with the software Xpowder (version 2004.04.44 PRO) for the qualitative and quantitative analysis.

Three techniques were used to characterize the porous network of the samples: mercury intrusion porosimetry (MIP), digital image analysis (DIA), and computer-aided simulation (CAS). MIP was performed with an AUTOPORE IV 9500 porosimeter, obtaining the samples' specific surface, pore access radius, percentage of connected porosity, and real density. DIA was performed by impregnating the samples with resin and then quantifying the resin-filled pores with SEM microscope, following the procedure detailed in Cárdenes et al. (2012). Last, CAS was performed with the program Pore-Cor Research Suite, v 6.31. Using the data obtained from the MIP curves, the program models a 3D structure of the rock, measuring the tortuosity and connectivity parameters, among many others (Laudone et al. (2008).

\section{Weathering tests}

From each variety, 12 cubes of $5 \times 5 \times 5 \mathrm{~cm}$ were cut. Six of them were used for the SC test, and the other six for the FT test. The SC test was performed according to EN 12370 Natural Stone Methods. Determination of resistance to salt crystallization, consists in submerging the samples in a $14 \%$ 

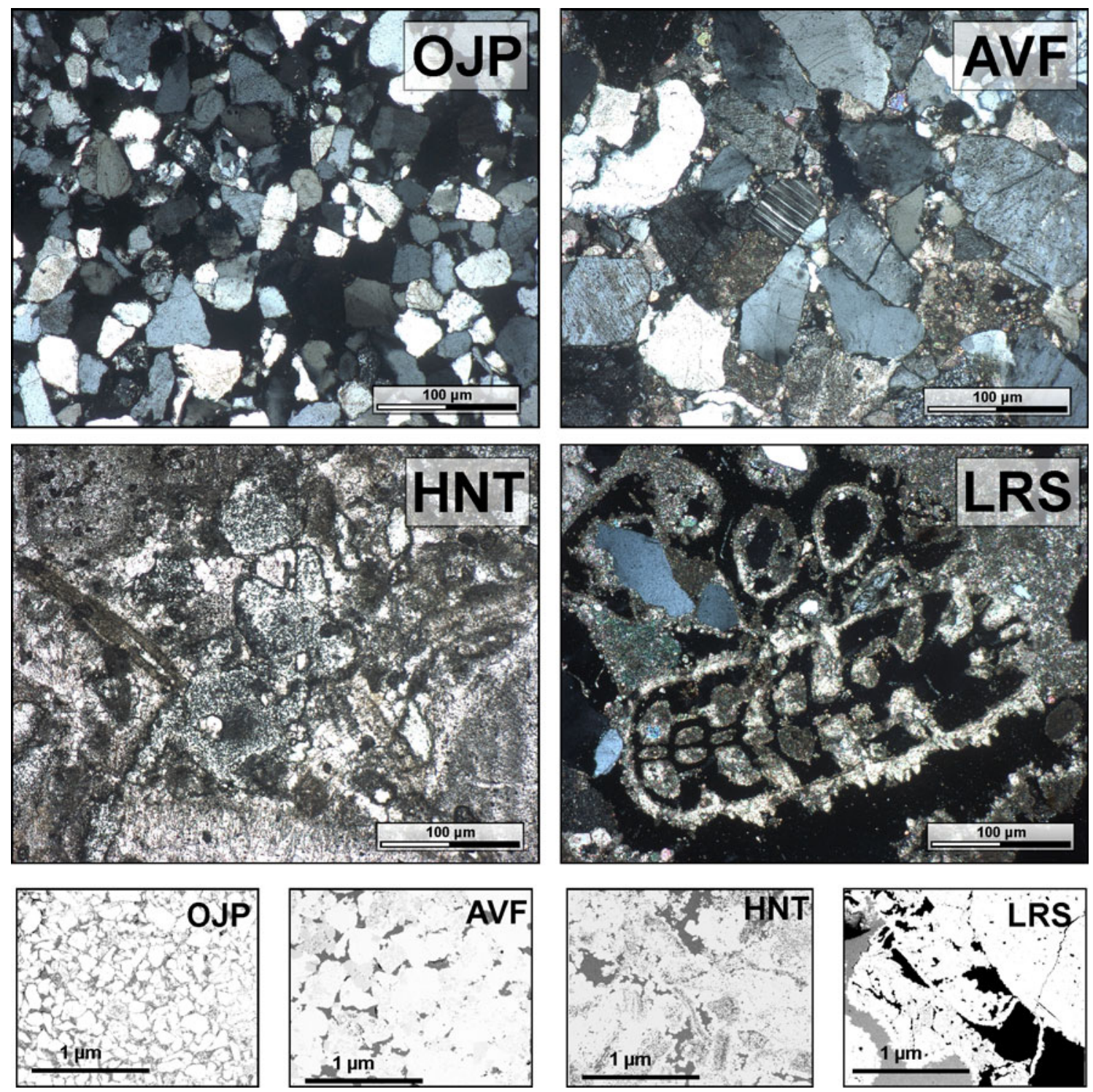

Fig. 3 Polarized microscope images of four selected rocks, with different textures: OJP and AVF, grain supported texture, HNT, and LRS bioclastic texture. For further information see Table 2. Bottom

sodium sulfate decahydrate solution ( $14 \mathrm{~g}$ of $\mathrm{Na}_{2} \mathrm{SO}_{4}$. $10 \mathrm{H}_{2} \mathrm{O}$ and $86 \mathrm{~g}$ of $\mathrm{H}_{2} \mathrm{O}$ ) for $2 \mathrm{~h}$ at $20^{\circ} \mathrm{C}$. Afterwards, the samples are stored in an oven at $105{ }^{\circ} \mathrm{C}$ for $16 \mathrm{~h}$, with high background humidity. The temperature of the oven is reached gradually, increasing progressively over the first 10-15 h. After the first cycle, the rocks are stored for cooling for $4 \mathrm{~h}$, thus completing a $24-\mathrm{h}$ cycle. The complete test is comprised of 15 cycles. For the FT test, the norm used as a reference was EN 12371 Natural Stone Methods. Determination of frost resistance The samples were initially dried and then submerged in distilled water at $20^{\circ} \mathrm{C}$ for $6 \mathrm{~h}$. After this time, samples were placed in a freeze chamber at $-12{ }^{\circ} \mathrm{C}$ for other $6 \mathrm{~h}$. These two steps comprise one cycle. With regard to the number of cycles to be performed, the norm small images correspond to quantification of the pore diameter by resin impregnation

distinguishes between technological essay and characterization test, which have different requirements. Goudie (1999) uses 80 cycles in his study, but for the present study we continue until 100 cycles to guarantee that at least $2 / 3$ of the samples were affected by the FT test, approximately the same proportion as for the SC test. In order to monitor the physical changes produced in the samples, all the edges of the cubes were painted with black ink, so the fragmentations or losses of material would be easily seen.

\section{Alteration quantification}

To quantify the alteration of the samples, an alteration index based on visual observations was used. Depending 
Table 3 Pore system characterization of the bulk samples

\begin{tabular}{|c|c|c|c|c|c|c|c|c|c|}
\hline Sample & $\begin{array}{l}\text { Specific } \\
\text { surface } \\
\left(\mathrm{m}^{2} \mathrm{~g}^{-1}\right)^{\mathrm{a}}\end{array}$ & $\begin{array}{l}\text { Pore } \\
\text { diameter } \\
(\mu \mathrm{m})^{\mathrm{b}}\end{array}$ & $\begin{array}{l}\text { Radius access } \\
\text { pores }(\mu \mathrm{m})^{\mathrm{a}}\end{array}$ & $\begin{array}{l}\text { Connected } \\
\text { porosity }(\%)^{\mathrm{a}}\end{array}$ & $\begin{array}{l}\text { Real density } \\
\left(\mathrm{g} \mathrm{cm}^{-3}\right)^{\mathrm{a}}\end{array}$ & $\begin{array}{l}\text { Connec } \\
\text { tivity }^{c}\end{array}$ & $\begin{array}{l}\text { Tortuo } \\
\text { sity }^{\mathrm{c}}\end{array}$ & $\begin{array}{l}\text { SC } \\
\text { alteration } \\
\text { index }\end{array}$ & $\begin{array}{l}\text { FT } \\
\text { alteration } \\
\text { index }\end{array}$ \\
\hline ESP & 1.17 & 7.89 & 0.10 & 6.96 & 2.46 & 3.04 & 3.30 & 9.06 & 10.00 \\
\hline PCF & 0.59 & 9.14 & 0.26 & 9.38 & 2.43 & 3.25 & - & 9.11 & 10.00 \\
\hline OJP & 0.51 & 12.56 & 0.44 & 12.93 & 2.33 & 3.64 & 3.10 & 8.50 & 10.00 \\
\hline PIT & 1.12 & 16.01 & 0.17 & 10.99 & 2.47 & 3.38 & 3.60 & 8.50 & 10.00 \\
\hline BAF & 0.39 & 12.52 & 0.54 & 11.14 & 2.19 & 3.75 & 4.20 & 9.89 & 10.00 \\
\hline Average & $0.76(0.36)$ & $\begin{array}{l}11.62 \\
(3.20)\end{array}$ & $0.40(0.38)$ & $10.28(2.24)$ & $2.38(0.12)$ & $3.41(0.29)$ & $3.55(0.48)$ & $9.01(0.57)$ & $10(0.0)$ \\
\hline AVF & 1.34 & 7.56 & 0.04 & 17.09 & 2.49 & 3.40 & - & 4.00 & 10.00 \\
\hline VLD & 1.61 & 0.21 & 0.20 & 17.82 & 2.22 & 3.88 & - & 2.61 & 6.80 \\
\hline SIL & 2.49 & 0.03 & 0.03 & 21.50 & 1.92 & 2.90 & 2.70 & 2.06 & 10.00 \\
\hline BRY & 2.63 & 0.15 & 0.15 & 21.72 & 2.13 & 2.93 & 5.30 & 3.56 & 8.62 \\
\hline BAM & 3.59 & 8.50 & 0.10 & 18.55 & 2.20 & 3.14 & 3.70 & 4.39 & 6.34 \\
\hline BAZ & 5.27 & 7.02 & 0.04 & 12.90 & 2.33 & 3.17 & - & 3.83 & 9.33 \\
\hline NWY & 0.99 & 17.14 & 0.34 & 18.43 & 2.42 & 3.74 & 2.10 & 2.06 & 8.27 \\
\hline Average & $2.56(1.49)$ & $5.80(6.28)$ & $0.13(0.11)$ & $18.29(2.97)$ & $2.24(0.19)$ & $3.30(0.38)$ & $3.45(1.40)$ & $3.21(0.95)$ & $8.48(1.46)$ \\
\hline PAG & 0.27 & 10.24 & 1.75 & 24.03 & 2.55 & 4.78 & 3.80 & 2.61 & 2.54 \\
\hline DOU & 0.90 & 10.46 & 0.32 & 15.54 & 2.21 & 4.19 & 2.60 & 2.67 & 4.13 \\
\hline LSP & 3.42 & 7.38 & 0.21 & 33.38 & 1.87 & 3.34 & - & 2.28 & 1.15 \\
\hline PMU & 0.52 & 0.92 & 0.92 & 24.24 & 2.08 & 3.56 & 3.50 & 2.11 & 2.72 \\
\hline HNT & 0.21 & 2.44 & 2.44 & 25.32 & 2.04 & 3.64 & 3.10 & 3.94 & 2.08 \\
\hline RSS & 0.92 & 15.88 & 0.24 & 21.34 & 2.07 & 3.56 & 3.50 & 1.33 & 2.28 \\
\hline Average & $1.04(1.20)$ & $7.89(5.56)$ & $0.98(0.93)$ & $23.98(5.80)$ & $2.14(0.23)$ & $3.84(0.54)$ & $3.30(0.46)$ & $2.49(0.85)$ & $2.48(0.97)$ \\
\hline LRS & 1.14 & 47.74 & 0.61 & 16.73 & 2.60 & 5.27 & 3.00 & 10.00 & 6.61 \\
\hline
\end{tabular}

Division of the rocks made by groups as in Fig. 4

In brackets: standard deviation. Parameters calculated by ${ }^{\mathrm{a}} \mathrm{MIP},{ }^{\mathrm{b}} \mathrm{DIA}$ and ${ }^{\mathrm{c}} \mathrm{CAS}$ (see text for further explanation)

on the material loss, a number was assigned to every sample and to every cycle. Only three stages of alteration were considered (Fig. 2) to simplify the measurements. Cubes with little to no alteration had a score of 2 , cubes with significant alteration on their edges had a score of 1 , and cubes with the edges completely destroyed had a score of 0 . After each SC and FT cycle, all the cubes were examined and scored, and the average for each cycle was calculated. The final score for each stone was recalculated to a 10 scale, obtaining the alteration quantification index. Other studies have used similar visual methods for calculating different alteration indices, e.g. (Angeli et al. 2007).

\section{Statistics}

The statistical analysis was carried out with the program SPSS v.15.0 for Windows, using the Pearson's correlation index. This statistical correlation was chosen assuming that the relationships between the variables are linear.

\section{Results and discussion}

The petrographical and mineralogical analyses (Table 2) of the rocks show different sedimentary lithologies (sandstones and carbonates) with different textures (grain supported, crystalline and bioclastic, Fig. 3). The determination of the pore system (Table 3; Fig. 4) shows a wide range of rocks with different average pore diameters, between $0.03 \mu \mathrm{m}$ (SIL) and $47.74 \mu \mathrm{m}$ (LRS). More than half of the rocks have pore diameters below $10 \mu \mathrm{m}$ (data obtained by DIA), which is held to be the threshold after which alteration processes become especially harmful. Connectivity and tortuosity values are rather high. In regard to tortuosity, the CAS algorithm was not always able to determine rocks' tortuosity value, since in some cases Pore-Cor's iterative algorithms are unable to determine a value for a unit cell.

The results of the rocks for the Alteration Quantification in both tests are displayed in Fig. 5. In this graph, three 

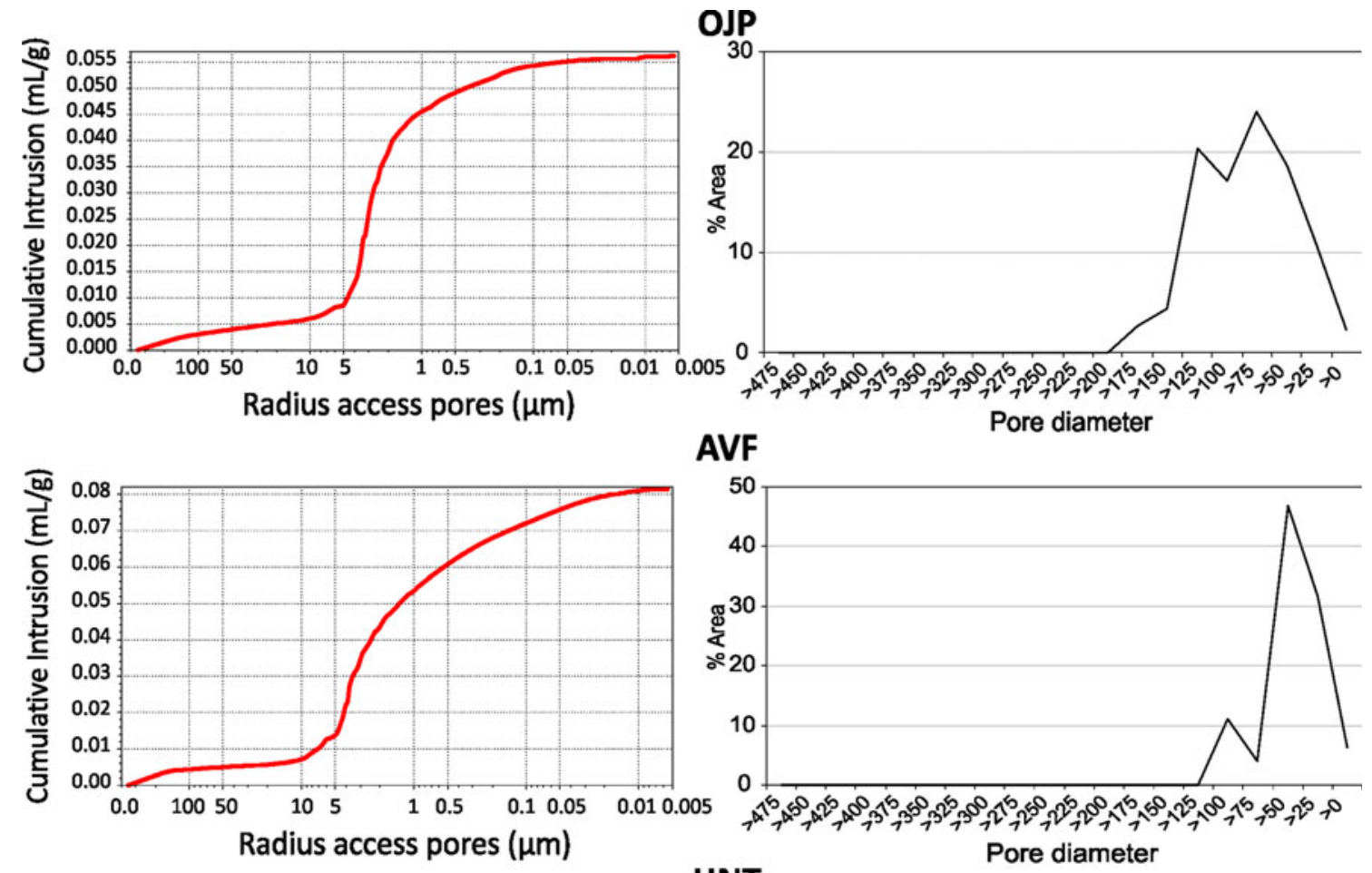

AVF
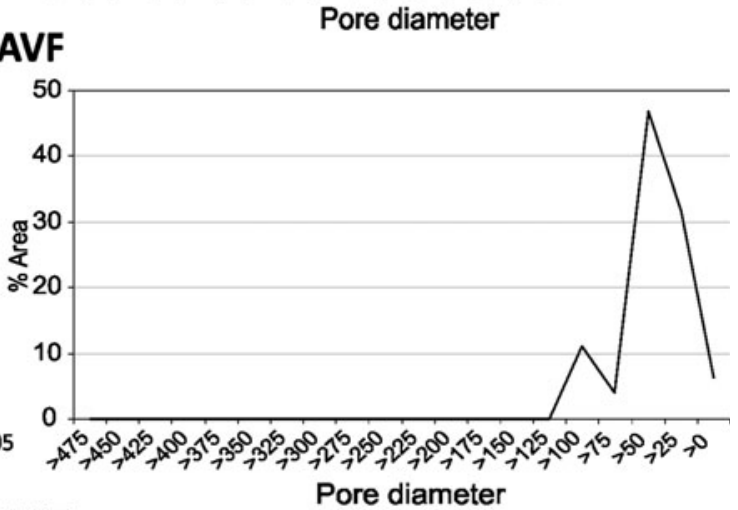

HNT
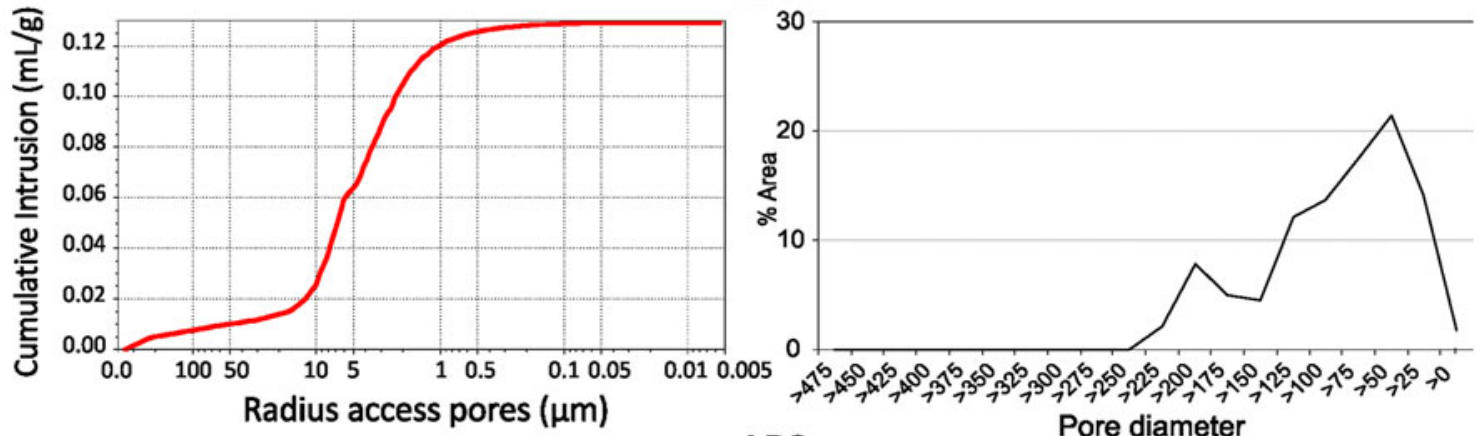

LRS

Pore diameter
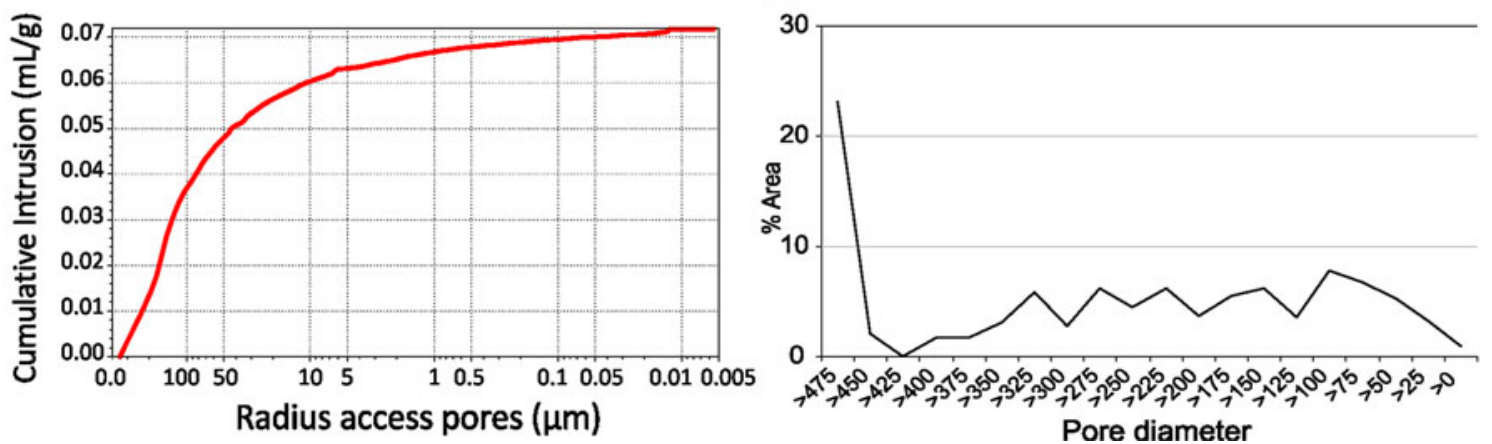

Fig. 4 Cumulative intrusion vs. pore size (MIP) of four selected rocks which showed different behaviors to both SC and FT tests

main groups can be distinguished. Group A represents the rock with the highest values for both tests, those which did not show any alteration, group B is for the rocks which had good results for the FT test but poor results for SC, and group $\mathrm{C}$ is for the rocks with poor results in both tests. There is one rock which does not fit any of these three groups, LRS, a lumachelle with macroporosity. Rocks with macroporosity are considered to be moderately durable, and are more vulnerable to the physical weathering than to the chemical one (Yavuz 2012).

Groups $\mathrm{A}$ and $\mathrm{C}$ are virtually equal, since they are made up of rocks that had the same response to both tests. All but one of the sandstones used in this study (AVF) belong to one of these two groups; in fact, group A contains only 


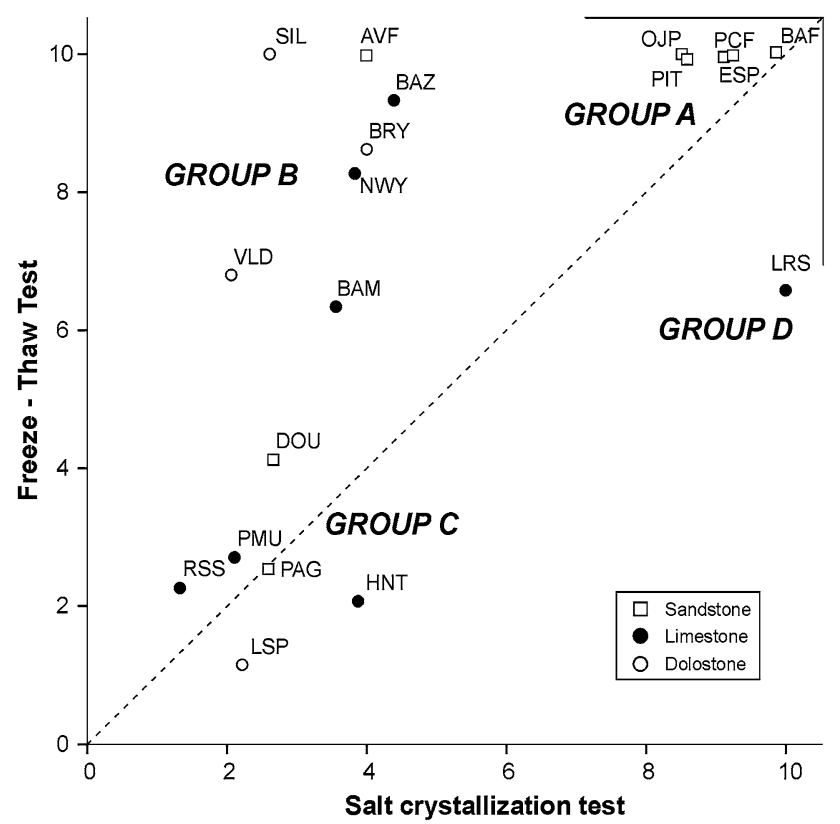

Fig. 5 Results for the alteration quantification for the rock samples to the Salt crystallization and freeze-thaw tests. The dashed line indicates when rocks have the same response to both tests sandstones. Groups B and C are more heterogeneous, as all of the carbonate stones fit into one of these two groups, as well as some of the sandstones. Thus, carbonate stones all have low resistance to $\mathrm{SC}$, but different levels of resistance to FT. For rocks close to the dashed line, both the SC and FT tests can be considered equivalent. This can be assumed for groups $\mathrm{A}$ and $\mathrm{C}$, or in other words, for most of the sandstones used in this work. Carbonate rocks behave differently, so in their case the tests cannot be taken as equivalents. In terms of the morphology of the altered rocks, FT causes straight fractures, while SC causes disaggregation and rounding of the cubes, as observed in the rocks during both tests (Fig. 6). Regarding AVF, this sandstone is the only one which presents clay cement. As some authors have pointed out (Labus and Biochen 2012), sandstones with this type of texture have different behavior against weathering than sandstones with silica-cement.

The inter-parameter correlations are displayed in Tables 4 and 5. Table 4 takes into account all the samples, and shows significant correlations between the alteration indices of SC and FT, while Table 5 takes into account only groups $\mathrm{A}$ and $\mathrm{C}$, the two groups that were the most
Fig. 6 Idealized graphical evolution of the selected rocks during the weathering tests. In brackets the final score for the alteration quantification index achieved for each rock.

Sandstone OJP and limestone HNT showed a quite similar performance for both tests, while sandstone AVF did not show correlation. On the other hand, the high porous LRS lumachelle showed a very low correlation for the weathering tests
Salt Crystallization cycles
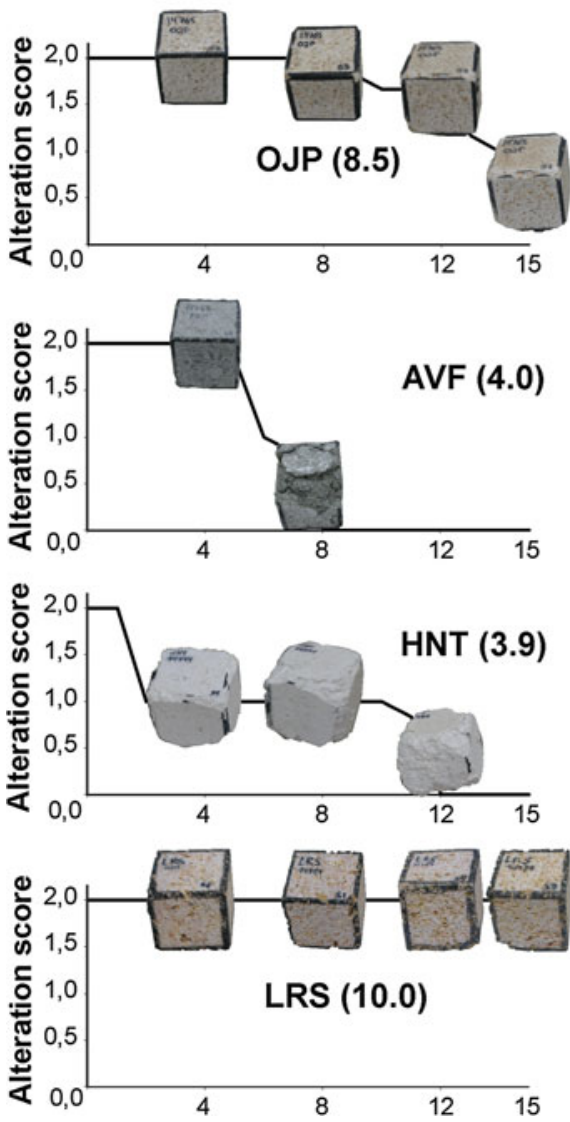

Freeze-Thaw cycles
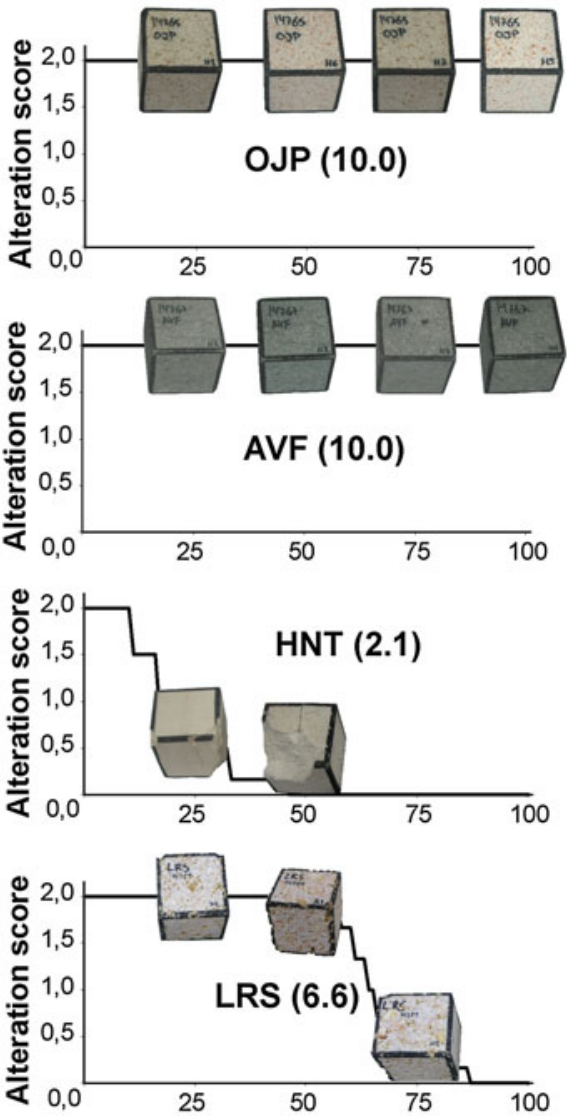
Table 4 Bivariate Pearson's correlation between the parameters of the porous system for all the samples $(n=19)$

\begin{tabular}{|c|c|c|c|c|c|c|c|c|c|}
\hline & $\begin{array}{l}\text { Specific } \\
\text { surface }\end{array}$ & $\begin{array}{l}\text { Pore } \\
\text { diameter }\end{array}$ & $\begin{array}{l}\text { Radius access } \\
\text { pores }\end{array}$ & $\begin{array}{l}\text { Connected } \\
\text { porosity }\end{array}$ & Density & Connectivity & Tortuosity & $\begin{array}{l}\mathrm{SC} \\
\text { alteration }\end{array}$ & $\begin{array}{l}\text { FT } \\
\text { alteration }\end{array}$ \\
\hline Specific surface & 1 & -0.193 & $-0.523^{*}$ & 0.146 & -0.268 & -0.444 & 0.243 & -0.268 & 0.115 \\
\hline Pore diameter & & 1 & -0.013 & -0.237 & $-0.549 *$ & $-0.685^{* *}$ & -0.267 & $0.511 *$ & 0.036 \\
\hline Radius access pores & & & 1 & 0.325 & -0.034 & 0.444 & 0.033 & -0.028 & $-0.502 *$ \\
\hline Connected porosity & & & & 1 & $-0.617 * *$ & 0.074 & 0.067 & $-0.735 * *$ & $-0.774 * *$ \\
\hline Density & & & & & 1 & 0.453 & -0.114 & 0.550 & 0.420 \\
\hline Connectivity & & & & & & 1 & -0.244 & 0.119 & -0.361 \\
\hline Tortuosity & & & & & & & 1 & 0.081 & 0.065 \\
\hline $\mathrm{SC}$ alteration & & & & & & & & 1 & $0.614 * *$ \\
\hline FT alteration & & & & & & & & & 1 \\
\hline
\end{tabular}

* Correlation is significant at level 0.05

** Correlation is significant at level 0.01

Table 5 Bivariate Pearson 's correlation between the parameters of the porous system for groups A and C $(n=11)$

\begin{tabular}{|c|c|c|c|c|c|c|c|c|c|}
\hline & $\begin{array}{l}\text { Specific } \\
\text { surface }\end{array}$ & $\begin{array}{l}\text { Pore } \\
\text { diameter }\end{array}$ & $\begin{array}{l}\text { Radius access } \\
\text { pores }\end{array}$ & $\begin{array}{l}\text { Connected } \\
\text { porosity }\end{array}$ & Density & Connectivity & Tortuosity & $\begin{array}{l}\mathrm{SC} \\
\text { alteration }\end{array}$ & $\begin{array}{l}\text { FT } \\
\text { alteration }\end{array}$ \\
\hline $\begin{array}{l}\text { Specific } \\
\text { surface }\end{array}$ & 1 & 0.019 & -0.501 & 0.418 & -0.457 & -0.373 & -0.247 & -0.222 & -0.253 \\
\hline Pore diameter & & 1 & -0.484 & -0.433 & 0.368 & 0.083 & 0.222 & 0.300 & 0.418 \\
\hline $\begin{array}{l}\text { Radius access } \\
\text { pores }\end{array}$ & & & 1 & 0.400 & -0.100 & 0.510 & 0.160 & -0.246 & -0.406 \\
\hline $\begin{array}{c}\text { Connected } \\
\text { porosity }\end{array}$ & & & & 1 & - & 0.280 & -0.040 & $-0.836^{* *}$ & $-0.921 * *$ \\
\hline Density & & & & & 1 & 0.193 & 0.183 & 0.548 & $0.626^{*}$ \\
\hline Connectivity & & & & & & 1 & 0.048 & -0.427 & -0.394 \\
\hline Tortuosity & & & & & & & 1 & 0.287 & 0.211 \\
\hline $\mathrm{SC}$ alteration & & & & & & & & 1 & $0.965 * *$ \\
\hline FT alteration & & & & & & & & & 1 \\
\hline
\end{tabular}

* Correlation is significant at level 0.05

** Correlation is significant at level 0.01

similar. Two types of correlations can be inferred, weak (significant at level 0.05) and strong (significant at level 0.01). For Table 4, there are weak negative correlations between specific surface and access radius to the pores and between density and pore diameter. The explanation for these correlations is purely geometric. As for strong correlations, there are negative correlations between connected porosity and density, as well as between pore diameter and connectivity. Again, the explanation for these correlations is geometric. However, the most interesting correlations found in this study have to do with the alteration quantification indices and rock parameters. There is a weak positive correlation between the pore diameter and the effects of the SC test, which suggests that the greater their pore diameters, the more rocks are susceptible to the effects of SC. For the FT test, a weak correlation holds between the access radius and pores. Since both tests affect the rocks in a similar way (i.e. by increasing the volume of a fluid phase inside the pore system), these correlations are to be expected in rocks with the same parameters. This is the case for the connected porosity, which has strong negative correlations with both SC $(-0.0735)$ and FT $(-0.774)$. These results highlight the role of connected porosity in rocks' weatherability, which has been pointed out in a number of previous studies. Taking one step forward, the correlations become clearer still if one considers only the rocks that were found to be equivalent with respect to the Alteration Quantification, i.e., groups A and C. In Table 5, which includes only these groups, the negative correlation between connected porosity and both alteration quantifications becomes stronger $(-0.836$ for $\mathrm{SC}$ and -0.921 for FT). These two groups represent sandstones and some carbonate rocks. Also, for these rocks, the SC and FT alteration quantifications have a high positive correlation (0.965), which shows that, for sandstones (regardless of one sample, AVF) and for some carbonates, 
the two tests can be considered equivalents. Finally, there is a negative correlation between density and connected porosity $(-0.651)$, which again can be explained as a question of geometry.

\section{Conclusions}

This visual method is based in the direct observation of the rocks' decay, instead of the measure of the weight variations, as used in other works. Thus, it has indeed been shown to provide reliable insight into the samples' degree of weathering. Freeze-thaw and salt crystallization tests have been proven to be equivalent for some sandstones and carbonates. In the case of sandstones, the texture and cement have an important role in the weathering. For silica-cement sandstones, both tests are correlated, but not for clay-cement sandstones.

In terms of weathering trigger factors, connected porosity appears to be the main factor behind weatherability: as it increases, weathering diminishes, in a negative correlation. This suggests that in a well-connected pore system, the effect of weathering caused by volume increase is lower than that in a low-connected pore system. One explanation could be that well-connected pore systems have a greater ability to accommodate. Last, salt crystallization had more devastating effects on the samples than freeze-thaw in most cases.

Acknowledgments This work was supported by the Spanish Ministry for Science and Innovation (MICINN) through the project PERDURABLE MICINN-09-CIT-380000-2009-25. Thanks also to Nicholas Callaway for his critical review of the manuscript.

\section{References}

Akin M, Özsan A (2011) Evaluation of the long-term durability of yellow travertine using accelerated weathering tests. Bull Eng Geol Environ 70:101-114. doi:10.1007/s10064-010-0287-x

Alves C, Figueiredo C, Maurício A, Braga MAS, Aires-Barros L (2011) Limestones under salt decay tests: assessment of pore network-dependent durability predictors. Environ Earth Sci 63:1511-1527. doi:10.1007/s12665-011-0915-1

Angeli M, Bigas JP, Benavente D, Menéndez B, Hébert R, David C (2007) Salt crystallization in pores: quantification and estimation of damage. Environ Geol 52:187-195. doi:10.1007/s00254006-0509-5

Angeli M, Benavente D, Bigas JP, Menéndez B, Hébert R, David C (2008) Modification of the porous network by salt crystallization in experimentally weathered sedimentary stones. Mater Struct/ Materiaux et Constructions 41:1091-1108. doi:10.1617/s11527007-9308-z

Angeli M, Hébert R, Menéndez B, David C, Bigas JP (2010) Influence of temperature and salt concentration on the salt weathering of a sedimentary stone with sodium sulphate. Eng Geol 115:193-199. doi:10.1016/j.enggeo.2009.06.001

Benavente D (2011) Why pore size is important in the deterioration of porous stones used in the built heritage. Macla 15:41-42
Benavente D, del Cura MAG, Fort R, Ordónez S (2004) Durability estimation of porous building stones from pore structure and strength. Eng Geol 74:113-127. doi:10.1016/j.enggeo.2004.03.005

Benavente D, Cueto N, Martínez-Martínez J, García Del Cura MA, Cañaveras JC (2007) The influence of petrophysical properties on the salt weathering of porous building rocks. Environ Geol 52:197-206. doi:10.1007/s00254-006-0475-y

Bortz SA, Wonneberger B (2000) Predicting the durability of building stone using accelerated weathering. ASTM Special Technical Publication, West Conshohocken, pp 116-132

Buj O, López PL, Gisbert J (2010) Characterization of pore system and their influence on decay rates caused by salt weathering on limestones and dolostones quarried in Abanto (Zaragoza, Spain). Materiales de Construcción 60:99-114. doi:10.3989/mc.2010. 50108

Cárdenes V, Mateos FJ, Paradelo R (2012) Degradability of building stone: influence of the porous network on the rate of dissolution of carbonate and evaporitic rocks. J Cult Heritage. doi:10.1016/j. culher.2012.05.003

Carr DD, Strickland J, McDonald WH, Bortz S (1996) Review of durability testing of building stone with annotated bibliography. J Test Eval 24:324-328

Doehne E (2002) Salt weathering: a selective review, pp 51-64

Goudie AS (1999) A comparison of the relative resistance of limestones to frost and salt weathering. Permafr Periglac Process 10:309-316. doi:10.1002/(sici)1099-1530(199910/12)10

La Iglesia A, González V, López-Acevedo V, Viedma C (1997) Salt crystallization in porous construction materials I estimation of crystallization pressure. J Cryst Growth 177:111-118

Labus M, Biochen J (2012) Sandstone degradation: an experimental study of accelerated weathering. Environ Earth Sci 67:20272042. doi: $10.1007 / \mathrm{s} 12665-012-1642-\mathrm{y}$

Laudone GM, Matthews GP, Gane PAC (2008) Modelling diffusion from simulated porous structures. Chem Eng Sci 63:1987-1996. doi:10.1016/j.ces.2007.12.031

Matsukura Y, Matsuoka N (1996) The effect of rock properties on rates of tafoni growth in coastal environments. Zeitschrift fur Geomorphologie, Supplementband 106:57-72

Mutlutürk M, Altindag R, Türk G (2004) A decay function model for the integrity loss of rock when subjected to recurrent cycles of freezing-thawing and heating-cooling. Int J Rock Mech Min Sci 41:237-244

Oguchi CT, Yuasa H (2010) Simultaneous wetting/drying, freeze/ thaw and salt crystallization experiments of three types of Oya tuff. Geological Society, London, Special Publications 2010, London, pp 59-72

Ordoñez S, Fort R, Garcia del Cura MA (1997) Pore size distribution and the durability of a porous limestone. Q J Eng Geol 30:221-230

Přikryl R, Lokajíček T, Svobodová J, Weishauptová Z (2003) Experimental weathering of marlstone from Přední Kopanina (Czech Republic)-historical building stone of Prague. Build Environ 38:1163-1171. doi:10.1016/s0360-1323(03)00073-8

Ruedrich J, Kirchner D, Siegesmund S (2011) Physical weathering of building stones induced by freeze-thaw action: a laboratory long-term study. Environ Earth Sci 63:1573-1586. doi:10.1007/ s12665-010-0826-6

Saad A, Guédon S, Martineau F (2010) Microstructural weathering of sedimentary rocks by freeze-thaw cycles: experimental study of state and transfer parameters. Comptes Rendus Geosci 342:197-203

Steiger M, Charola AE, Sterflinger K (2011) Weathering and deterioration. In: Siegesmund S, Snethlage R (eds) Stone in architecture: properties, durability, 4th edn. Springer, Berlin, pp 227-316

Stumm W, Morgan JJ (1981) Aquatic chemistry: an introduction emphasizing chemical equilibria in natural waters. Wiley, New York 
Takarli M, Prince W, Siddique R (2008) Damage in granite under heating/cooling cycles and water freeze-thaw condition. Int $\mathbf{J}$ Rock Mech Min Sci 45:1164-1175

Yavuz AB (2012) Durability assessment of the Alacati tuff (Izmir) in western Turkey. Environ Earth Sci 67:1909-1925. doi:10.1007/ s12665-012-1632-0
Yu S, Oguchi CT (2010) Role of pore size distribution in salt uptake, damage, and predicting salt susceptibility of eight types of Japanese building stones. Eng Geol 115:226-236. doi:10.1016/j. enggeo.2009.05.007 